Portland State University

PDXScholar

$1-2003$

\title{
The Interactive Work of Prosody in the IRF Exchange: Teacher Repetition in Feedback Moves
}

John Hellermann

Portland State University

Follow this and additional works at: https://pdxscholar.library.pdx.edu/ling_fac

Part of the Applied Linguistics Commons, and the Bilingual, Multilingual, and Multicultural Education Commons

Let us know how access to this document benefits you.

Citation Details

Hellermann, J. (2003). The Interactive Work of Prosody in the IRF Exchange: Teacher Repetition in Feedback Moves. Language In Society, 32(1), 79-104. doi:10.23074169241

This Article is brought to you for free and open access. It has been accepted for inclusion in Applied Linguistics Faculty Publications and Presentations by an authorized administrator of PDXScholar. Please contact us if we can make this document more accessible: pdxscholar@pdx.edu. 


\title{
The interactive work of prosody in the IRF exchange: Teacher repetition in feedback moves
}

\author{
J O H N H L L E R A N N \\ Department of Speech Communication \\ Southern Illinois University-Carbondale \\ Carbondale, IL 62901-6605 \\ jkheller@siu.edu
}

A B S T R A C T

This article examines the interactive import of prosody from a perspective of participants' orientation to talk in interaction, taking advantage of data from institutional discourse to focus on the prosodic packaging of recurring turn sequences of the same discourse activity. The analysis focuses on the third slot of a ubiquitous three-part classroom discourse sequence, the IRF exchange (Sinclair \& Coulthard 1975), a site in which teachers make repetitive feedback moves following student responses. Examination of more than 25 hours of classroom discourse and more than 300 third-turn teacher feedback types uncovered a systematic use of prosody for these teacher repetitions that coincides with a teacher's positive assessment of the student response. Further analysis shows that more complex prosodic packaging is used by teachers in their repetitive feedback turns to index other interactive functions. (Prosody, repetition, classroom discourse.)*

\section{N T R O D U C T I O N}

This article builds on the work of a group of researchers who have been interested in discovering the interactional work done by prosody in talk-in-interaction (Selting 1987, 1992, 1998; Couper-Kuhlen 1992, 1993, 1996, 1998; Local 1996; Schegloff 1996b, 1998). The analysis takes advantage of conversation analytic methods and acoustic analysis to uncover the prosody of repetition in an institutional setting, a high school classroom. There are two primary goals of the analysis. The first is to strengthen existing theories of prosody in English by collecting empirical evidence for the use of prosody in talk-in-interaction (Couper-Kuhlen \& Selting 1996, Schegloff 1998). There is a long history of analysis of prosody in language, but the bulk of this research has used language out of context as its data for analysis (Ladd 1996, Wichmann 2000; see Wennerstrom 2001 for a thorough review). The investigation of prosody from an interactive perspective does not attempt to make a oneto-one match of prosodic form with semantic, grammatical, or pragmatic meaning; instead, by looking at how prosody is used in language in use and taking advantage of the context as well as of participants' orientation to their prosody, this research seeks to uncover the interactive work that prosody helps to accomplish. 
The second goal of this research is to understand the role that micro-level linguistic phenomena such as prosody play in the establishment of classroom discourse practices by examining the complex constellation of interacting prosodic cues that occur with recurring linguistic moves during classroom interaction. The recurring nature of discourse moves in the classroom allows the isolation of discrete discourse contexts (Merritt 1994) in which these prosodic cues can be studied. By focusing on such recurring moves, we can gain an understanding of the interactive functions of prosody in the classroom, uncovering how different prosody accompanies and shapes recurring social practices of the discourse within which teaching and learning are accomplished. The recurring practice in the site for my investigation, classroom discourse, and the focus of this article, is the often-noted IRF exchange (Sinclair \& Coulthard 1975; Mehan 1979).

I R F EXCH A N G E

The ubiquitous, three-part IRF exchange (Initiation, Response, Feedback) has been said to account for as much as $70 \%$ of all classroom talk (Wells 1993), and it has been characterized as the exchange that constitutes the genre of classroom discourse (Lemke 1990, Wells 1999). The IRF exchange, illustrated in ex. (1) below, is part of a discourse hierarchy developed by Sinclair \& Coulthard (1975:28) and consists of three turns, or "moves" in sequence. The first turn in the exchange is an elicitation, directive, or informative. These types of moves are made most often by the teacher and are accomplished in the first turn of the exchange, the INITIATION move (lines 681-683 in ex. 1). The initiation moves are followed by some sort of student RESPONSE move. Following a teacher's directive or informative type of initiation move, the student response will likely be some kind of action: If a teacher makes a directive such as "turn to page 23," the students' response will likely be to turn the pages in the book; if the teacher is informing (giving a lecture), the student response may be note-taking. For an elicitation move, however, a verbal response is probable (ex. 1, lines 684-686). The move that follows a student verbal response is some kind of FEEDBACK from the teacher, which can accept or reject, evaluate, or comment on the student's response (Sinclair \& Coulthard 1975:48-49). In (1), the teacher feedback is in the form of a repeat of the student's response (line 687); based in part on its prosodic packaging (as the analysis will show), this can be classified as an evaluation.

(1) [12jen 687]

$\begin{array}{llll}\text { I } & 681 & \text { T: } & \text { if an object that's placed in front of a glass plate (.) } \\ & 682 & & \begin{array}{l}\text { will the image appear in front (.) of (.) or behind the } \\ \text { glass plate. }=\end{array} \\ & 683 & & \text { = behin [d. } \\ \text { R } & 684 & \text { Jim: } & \text { [behind. } \\ \text { R } & 685 & \text { Dory: } & \text { [behind. }= \\ \text { R } & 686 & \text { Jill: } & \text { T: } \\ \text { F } & 687 & \text { T: } & \text { =behind. (.) a candle is placed ten centimeters }\end{array}$




\section{Critiques of the practice of IRF exchanges}

The imbalance in number of turns between students and teacher in the IRF exchange has made this exchange a much studied and critiqued classroom practice. Drew \& Heritage 1992 have noted how classroom discourse, like courtroom discourse, is designed to minimize audience participation (p. 27), and classroom discourse researchers (Lemke 1990, Nystrand \& Gamoran 1991, Wood 1992, Nystrand 1997) have criticized the triadic exchange as a teacher-dominant practice that is detrimental for fostering meaningful student participation. Others, however, see this exchange as a useful tool with which teachers can use their status as facilitators in classrooms to guide a large number of students toward the common goal of dialogic learning (Mercer 1992, 1995, Newman et al. 1997, Wells 1999, Nassaji \& Wells 2000, Adger \& Hoyle 2001).

After observing the classrooms in my data set first hand and on video recordings, my feeling was that the three-part exchanges are not monolithic in their use and interactive consequences, and that the use of the IRF exchange has a number of consequences for student participation and learning. In order to get a clearer picture of how this dominant discourse exchange type unfolds in classroom talk, I have focused on the prosody within which these IRF exchanges are accomplished to uncover the role that prosody plays in constructing the context for and the results of these exchanges. As the analysis will show, participants in classroom discourse use and orient to the use of prosody in a systematic and often complex way. I will look at repetitions that occur in the third move of the IRF exchange, the teacher's feedback move. Prosody can be seen as part of the teacher's projection of an assessment in this third turn of the IRF exchange, showing that the way the IRF is embodied in prosody plays a role in determining the interactive result of the exchange.

\section{PREVIOUS RESEARCH ON REPETITION}

Repetition in spoken language has often been characterized in linguistics as indicating defective, hesitant, or disfluent language (Blankenship \& Kay 1964, Shimanoff \& Brunak 1977, Scollon \& Scollon 2001). Repeated words are seen as superfluous in formal linguistics' goal of identifying rule systems for the grammar of language. Following the standard procedure of generalization in theory building, rule writing emphasizes economy in the representation of linguistic forms. From this perspective of theory building, repeated words or phrases are discounted as redundant in much linguistic description; thus, in a formal representation of grammar, they have no lexico-semantic content. However, linguistic research focusing on the social production of language has found repetition to be an important element in the understanding of discourse cohesion, language production, and linguistic knowledge (Bolinger 1961, 1976, Jefferson 1972, Goffman 1974, Halliday \& Hasan 1976, Schegloff, Jefferson \& Sacks 1977, Norrick 1987, Tannen 1987, 1989, Simpson 1994, Schegloff 1996a). 
Prosody arises only as a peripheral issue in much of the previous research on repetition. This investigation seeks to illuminate the work that prosody does in concert with lexical repetition. Although repetition of lexical items may be a way of making connections between larger units of discourse that are more often recognized by the researcher, Chafe (1988:7) suggests that when lexical items are not repeated, a repetition of intonation contour and level, which he calls "prosodic echoing," may be used by speakers to help achieve this coherence. My research shows that in classroom talk, prosodic repetition or non-repetition works with lexical repetition for purposes of discourse organization. Goffman writes that speakers who repeat other's words have the option of using some of the non-lexical context - prosody, or in his words, the "expressive stream" (1974:537) - of those words in their repeat, and that this "mimicry" of the prosody has the effect of animating the original speaker of those words. If lexical items are repeated as "shadows" (Tannen 1987), they are repeated with a prosodic trajectory that either copies or differs in some way from the original utterance, and in this way, the repeats influence the discourse to follow. Simpson 1994 posits that "shadowing"-type repetitions repeat the intonation contour of the initial speaker, but admits that she lacks data to back up this claim. The present analysis is a step toward uncovering evidence for how varying prosodic production is used with lexical repetition to accomplish different kinds of interactive work.

Speakers who repeat others' words have the choice of transparently mimicking the words and prosody of the original speaker, but when they repeat another's words, the mimicry that Goffman mentions is usually done much more subtly. In talk-in-interaction, repeaters rarely mimic overtly the original words and sounds of a previous speaker, yet a second speaker - a potential repeater - always orients to the prosody of the original utterance and displays that orientation in the prosodic production of the repetition (Couper-Kuhlen 1996, Auer et al. 1999). Just as we do not speak without prosody, we do not perceive spoken language without its prosody. Therefore, even when repeaters do not exactly copy the prosody of the original, in doing "not copying" they may display a stance with respect to the prosody of the original utterance, such as expressing affiliation or disaffiliation with previous talk.

Recent analyses that look closely at particular genres of talk-in-interaction have uncovered systematic uses for different prosodic packagings in repetition. Tarplee 1996 investigated interaction between caretaker and child during the activity of storybook reading/showing. After highlighting objects in the books to the children, the caretakers repeat the child's utterance. Tarplee found that the children orient to the prosody of the caretaker's repetitions. If the caretaker's repetition follows a gap, and if the prosody of the repetition contrasts intonationally with the child's original utterance, the child takes the repeats as a prompt for a different answer. Caretaker repetitions with non-contrastive prosody (that is, repetitions that match pitch and are rhythmically synchronized) are taken by children as affirmations of their candidate answers. 
Couper-Kuhlen, a longtime advocate for research into the interactive import of prosody in language in use (cf. 1990, 1992, 1993, Couper-Kuhlen \& Auer 1988 , 1991), investigated the intonation of repetition in radio call-in game-show events (1996), finding that participants in talk-in-interaction make very subtle distinctions with respect to pitch height. Her analysis showed that talk-show hosts used pitch height matching on a relative scale, ${ }^{1}$ but that for different interactive import, they used absolute pitch matching. The callers, whose answers the talkshow host was repeating, were shown to orient in their responses to these differences in the host's type of pitch matching.

Researchers working on repetition in classroom discourse (Orsolini \& Pontecorvo 1992, Bean \& Patthey-Chavez 1994) have focused on the different roles that teacher feedback moves play in evaluating student responses and encouraging further student talk. Bean \& Patthey-Chavez note that the role of prosody in shaping teacher repetition differs depending on the teacher's desired evaluation of the student response. Their discussion, however, does not offer any more detail on how prosody may work to shape the different evaluations of teachers. Norrick describes repetitions as a neutral, objective way for the teacher to "insure comprehension by the whole group ... signalling neither affirmation nor agreement with their original" (1987:253). As the following analysis will show, however, because of the sequential placement of the teacher repetition following a student response, the teacher repetition cannot be neutral. In the classroom, ${ }^{2}$ a teacher's repetition of a student's words acknowledges and evaluates student participation (Sinclair \& Brazil 1982) while reshaping or revoicing that participation to meet the subject-matter agenda of the teacher, and, finally, to shape the trajectory of the immediately following discourse. The systematic use of prosodic cues with these repetitions allows for the co-construction of some kind of assessment of the student response by the teacher. We will see how the prosody ${ }^{3}$ as part of the teacher's lexical repetitions contributes to these functions. A set of prosodic cues used with teacher repetitions in IRF exchanges emerges to accompany a particular discourse function: giving a positive assessment of a student response. In marking student responses as less than complete, or incorrect, teachers repeat student responses using a different set of prosodic cues. Pitch and timing can be seen, then, as primary linguistic resources employed by the teacher to accomplish other interactive work.

This article looks at "other"-repetition (Tannen 1987, 1989, Johnstone 1994, Schegloff 1996a) - specifically, the lexical items in the third slot of the three-turn IRF exchange that repeats the lexical items in the second slot. In the classroom, this is the teacher's repetition of a student response. A focus on linguistic repetition could look at the repeats of phonological, lexical, or syntactic forms that recur at any point in subsequent spoken text, but this investigation is limited to teacher repetition of a lexical item or items (accounting for the appropriate change in pronouns) that occur in the immediately local context of the talk - that is, the teacher's repeating the immediately preceding turn. Prosodic features of pitch 
level and timing are most easily associated with lexical items, and the focus on lexical repetition makes the objects of analysis more transparent to readers (cf. Schegloff 1996a). In the classroom, this type of lexical repetition most often occurs in the immediately following turn at talk, as depicted in (2), lines 13 and 14:

(2) [6jen 16:12]

$\begin{array}{llll} & 12 & \text { T: } & \text { you have the hammer, the anvil and the, } \\ \rightarrow & 13 & \text { Dina: } & \text { stirrup. } \\ \rightarrow & 14 & \text { T: } & \text { stirrup. okay so there's three little bones. (.) }\end{array}$

DATA AND METHODS

\section{Data}

I have analyzed in detail 25 hours of discourse in two different classrooms: a grade 12 physics class, and a grade 11 American history class in an urban public high school in the US Midwest. Each class had between eight and twenty students present on any given day, and each teacher had over twenty years of classroom teaching experience. ${ }^{4}$ The data are taken from two High- 8 video recordings. One camera recorded the classroom interaction from the front of the class, while a second camera was placed in the back of the classroom to follow the teacher. The video images from each camera were then overlaid to put a picture within a picture, and then digitized. The resulting digital recording includes the images and audio from both cameras, which ensured that most student talk in the classroom could be heard. ${ }^{5}$

\section{Analysis methods}

My analysis draws on work from several research traditions within the broadly defined field of discourse analysis, in an attempt to deepen the analysis of prosody in language. The analysis incorporates the fundamental tenets of Conversation Analysis; one is that the analysis of language is best done by describing the turn-by-turn sequence of talk to uncover the orientation of the participants to the particular instance of talk-in-interaction under study (Sacks, Schegloff \& Jefferson 1974, Atkinson \& Heritage 1984). For this study, detailed transcriptions were made independently by another analyst, using the transcription conventions of Conversation Analysis as outlined in Psathas 1995. After repeated viewings of the data, I made revisions of the transcripts and added detailed notation of the prosody in IRF exchanges. ${ }^{6}$ The analysis also takes advantage of the observations and the discourse and pitch categories established by the Birmingham school (cf. Sinclair \& Coulthard 1975, Brazil 1976, 1997). The close sequential analysis is intended to understand the process through which these categories can be established.

The study also takes advantage of acoustic readings of the audio tracks of the classroom discourse to graphically illustrate rhythm (showing the timings between prominences) and intonation (tracks of fundamental frequency). The acous- 
tic analysis was done by digitizing sound samples from the original High-8 video recordings with software available for personal computer (PRAAT 3.9.28, (P) Paul Boersma and David Weenink). The analog sound waves from the videotape were sampled at a rate of $22,000 \mathrm{~Hz}$, or 22,000 samples per second, and quantization at a bit rate of 16 .

\section{Categories of analysis}

Intonation contour. Fundamental frequency, the pitch of the speaker's utterance, will be presented in a scale of semitones ('t Hart, Collier \& Cohen 1990, Couper-Kuhlen 1996). An analysis of intonation using semitones instead of hertz (the acoustic unit of the measurement for fundamental frequency) acknowledges that intonation is not perceived by humans purely acoustically. The semitone scale is logarithmic in nature, accounting for the fact that changes in pitch at higher frequencies are perceived as smaller in degree than they are measured acoustically, in an absolute scale in hertz (Auer 1996, Couper-Kuhlen 1996). The analysis uses a relative scale of semitones to allow measurements of pitch to be compared across speakers who have very different pitch ranges (men vs. women, adults vs. children). For this reason, a scale in relative semitones is a useful analytical tool. There is also empirical support for distinguishing between relative and absolute pitch in semitones. Participants in talk-in-interaction have been shown to orient to the pitch level of other participants in both absolute and relative terms (Couper-Kuhlen 1996). For a cross-speaker comparison measured in relative semitones, the pitch ranges of the different individual speakers were determined by noting the highest and lowest recorded pitch for each speaker in the data set (in semitones). When a pitch track was made of a particular speaker, and that pitch track was to be compared with those of other speakers, the pitch track was plotted onto a single scale of relative semitones (0-24). For example, if a female teacher has a pitch range between 10 and 30 semitones, her individual maximum pitch height (30 semitones) would be indicated on a relative semitone scale as 24 semitones, while her individual minimum pitch (10 semitones) would be indicated on the relative scale as 0 semitones. All pitches in between are calibrated accordingly.

Pitch level divisions: $H-M-L$. The representation of pitch in relative semitones is made on a scale for minimum of 0 to a maximum of 24 . I have chosen this range based on intonation scholarship, which has often divided speakers' pitch ranges into three levels: high, mid, and low ranges (Brazil, Coulthard \& Johns 1980, Brazil 1997). The range 0-24 allows the interpolations into relative semitones to be divided equally into three parts of 8 semitones each. The scale I am using is a first step in incorporating Couper-Kuhlen's (1996) use of a scale in relative semitones with the kind of cross-speaker comparison of pitch level done by Brazil. I believe the usefulness of this scale can be tested empirically to de- 


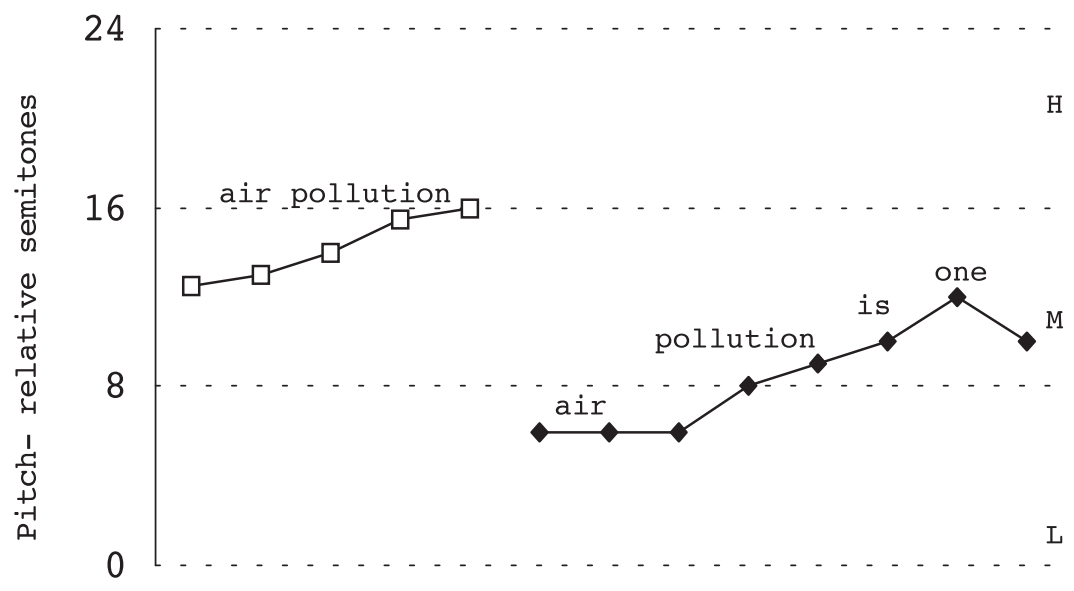

FIGURE 1: Pitch contours of 2 speakers at different pitch levels.

termine whether speakers in talk-in-interaction use or orient to such categories. The findings presented here support the reality of a tripartite division of speaker pitch range. Figure 1 illustrates the graphic display of pitch level and contour.

The graph in Figure 1 shows the intonation contour of two speakers. The $\mathrm{X}$ axis represents time, and the $\mathrm{Y}$ axis shows pitch level in relative semitones. The $\mathrm{H}, \mathrm{M}$, and $\mathrm{L}$ on the right side of the graph show the areas of pitch range. In the example, the intonation unit of the first speaker (a student giving an answer air pollution to a teacher's question) is represented by the square data points as a rising contour in mid pitch level. The intonation unit of the second speaker (a teacher giving feedback to the student's response), represented by the diamond data points, starts in the low pitch range and moves into the mid pitch range, where the pitch accent (pitch movement and prominence) is on the word one.

Pitch-level matching. Research on prosody has included analysis of the interactive value of pitch-level matching, or pitch concord (Brazil et al. 1980, Couper-Kuhlen 1996, Tarplee 1996, Cowley 1998). Much previous research on intonation focuses on the nuclear syllable of the tone unit as the site for discussing pitch height or level (Crystal 1969, Pierrehumbert 1980, Couper-Kuhlen 1986). It is the nuclear pitch that determines prominence for the intonation unit and that is used by the speaker to place focus on a lexical item. I have found CouperKuhlen's (1996) work looking at "register," or pitch-level matching, to be a more productive analytical tool for my data. ${ }^{7}$ Here, I will consider pitch matching (an abbreviation of the more accurate "pitch-level matching") to be instances when the nuclear syllable of the incoming speaker's intonation unit is in the same "global" pitch range (Couper-Kuhlen 1996) as the nuclear syllable in the previous speaker's last intonation unit. 


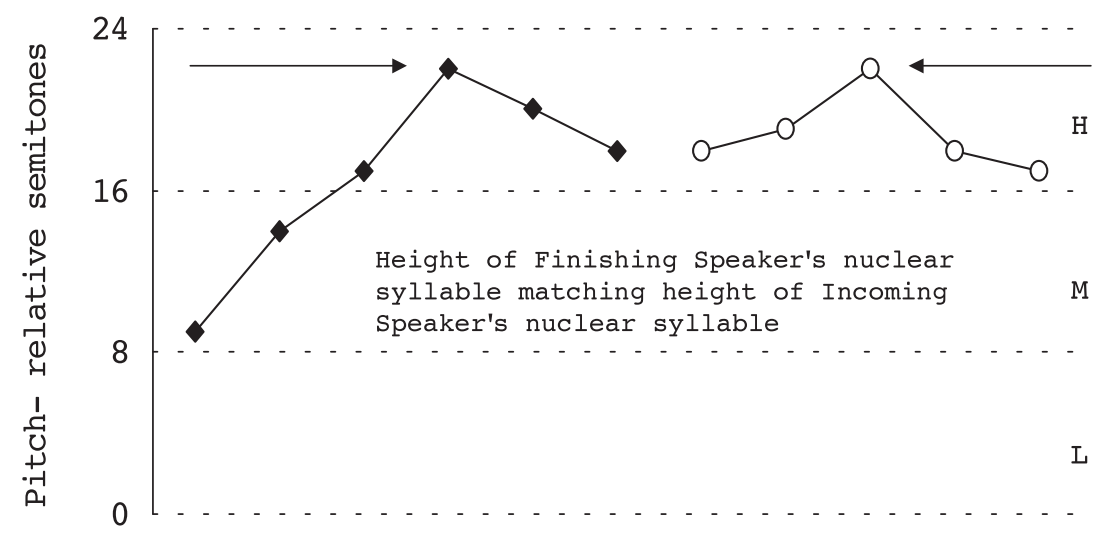

FIGURE 2: Pitch level matching.

Figure 2 gives an example of my operational definition of pitch matching. The first intonation unit starts in mid pitch range but has a nuclear syllable in the high pitch range. The second speaker's intonation unit starts in the low pitch range but moves to the exact level of the first speaker for the nuclear syllable.

Timing: Rhythm, pause, duration, speech rate. I will also follow CouperKuhlen's procedure (1993; see also Auer et al. 1999) for perceiving and notating rhythm in talk-in-interaction. According to Auer et al. 1999, the discussion of rhythm needs to take into account that the individual sound components that constitute prominence in English are all taken in by the participants in talk-ininteraction and processed so that prominence - and the regularly timed prominence of rhythm - can be perceived only in the context of the talk-in-interaction. For the purpose of this analysis, then, regularly timed prominences (rhythm) are noted only when perceived by the analyst after repeated hearings. Acoustic analysis is used for precise timing of duration between stressed syllables, but the tempo of the rhythm of some talk-in-interaction cannot be determined until participants and analyst have decided if there is a rhythmic stretch of talk. Duration of words is measured in milliseconds from the onset of the initial segment to the offset of the final segment. The pace or speech rate of a stretch of talk is determined by dividing the number of syllables in that stretch by time and is given in syllables per second (Gósy 1991, Uhmann 1992).

\section{DATA ANALYS IS}

In preliminary work, I noted all instances of third-turn repetition (by teacher and student) of preceding student turns. I noted almost 300 instances of adjacent third-turn repetition. As might be expected in classroom discourse, examples of 
TABLE 1. Environments of teacher repetitions.

Teacher repeats student after:

(1) Student response in IRF exchange

(2) Student questions, clarification checks, collaborations and comments 44

(3) Student "offending" words (includes mispronunciations) 9

(4) Others

teachers repeating student utterances occur more than any other type of repetition - 177 instances - and it was this subset of the data that I chose to work with. Within the subset of teacher repetitions of students, I have classified four different interactive situations that occurred in the data, listed in Table 1.

Of all the instances of teacher third-turn repetition of students in the data, most (111 of 177, or 64\%) occur as the third part of the IRF exchange, category (1) in Table 1 . The focus for my analysis was determined in part by this high rate of occurrence as a feedback move in IRF exchanges, as well as by a desire to understand how these repetitions are accomplished prosodically, and what interactive work may accompany different prosodic packagings.

\section{Prosody as a cue for positive assessment}

The examples of teacher repetitions in IRF exchanges highlighted in the analysis were chosen as representative of the interactive work that prosody accompanies in classroom discourse. Previous researchers have commented that teachers may use "repetition with differential intonation to challenge less desirable responses and confirm or ratify desirable ones" (Bean \& Patthey-Chavez 1994:218). The first two examples, (3) and (4), show what emerged as a prosodic pattern for teacher repetitions of student responses that are oriented to as positive assessment. Different settings of four prosodic resources - pitch contour, pitch level, timing, and rhythm - are used in teachers' repetitive feedback moves to mark the repeat as either a positive, negative, or equivocal assessment of the student responses they follow. Indicators of positive assessment are as follows:

(a) Rhythmical placement in synch with student response

(b) Falling pitch contour

(c) Mid level pitch

(d) Longer duration than student responses

In (3), from a grade 11 American history class studying mid-19th-century European settlers' encounters with the Native Americans, students are answering questions from a worksheet. The teacher and the class are engaging in a series of IRF exchanges, expanding on the information on the worksheet. This example 
shows a lexical repetition in the teacher's feedback move embodied in a prosodic packaging used as part of the linguistic expression of a positive evaluation. In (3), line 10, the teacher acknowledges Lourdes's response to the question she has read from the worksheet (right). The teacher continues in lines 10-14, asking an expansion question on the topic of Lourdes's response. At lines 15 and 16, Jill and Faith respond. The teacher's feedback move in line 17 is a lexical repetition of Faith's response. The first prosodic feature of the feedback that gives the talk in (3) an affiliative quality is its rhythmic placement.

(3) [34pen 14:42]

8 Lourdes: b? the coming of the railroad led to the destruction of the

9 buffalo and the Indians' way of life?

10 T: right. when the

11 /buffalo's

$12 \quad /$ gone

13 /what didn't they

14 /have.

15 Jill: $\quad /($ I know $)$

16 Faith: /food.

17 T: $\quad /$ food.

$18 \quad(1)$

19 T: number sixteen Mai.

The transcript in (3) is in a format outlining rhythmic feet. ${ }^{8}$ We see that the teacher's initiation move starts a rhythmic sequence of talk (lines 11 and 12) to which the students orient, placing their responses in synch rhythmically in the tempo started by the teacher's initiation. The teacher's feedback move (line 17), which ends the exchange, is also placed precisely within the rhythmic template established by the earlier teacher initiation (lines 10-14) and student response moves.

Investigations into the rhythm and tempo of talk-in-interaction have shown how participants orient to regularly timed stresses in preceding turns as one contextual cue (Scollon 1981, Erickson 1981, 1992, Erickson \& Schultz 1982, Fiksdal 1990, Couper-Kuhlen \& Auer 1991, Couper-Kuhlen 1992, 1993, Auer et al. 1999, Scollon \& Scollon 2001). Negotiated by the participants, the tempo of the rhythm in the talk varies to index different interactional work done in talk-ininteraction. Research on conversation has shown that participants in conversation use the prosodic cue of rhythm to make a "subjective gloss" (Couper-Kuhlen 1992) of the talk underway - that is, to position their utterance in some way with respect to what has happened before. The choice of speaking rhythmically or arhythmically seems to work to mitigate face threats in repair (Couper-Kuhlen 1992) as well as to organize conversational moves such as the receipt of news (Auer et al. 1999). Examples (3) and (4) show a discourse activity where the rhythmic placement of a turn is one of the prosodic cues that adds to the context of lexical repetition used by teachers to indicate positive evaluation.

Pitch level and contour also contribute to the construction of a positive assessment in sound. As Figure 3 shows, the teacher's response is at the middle pitch 


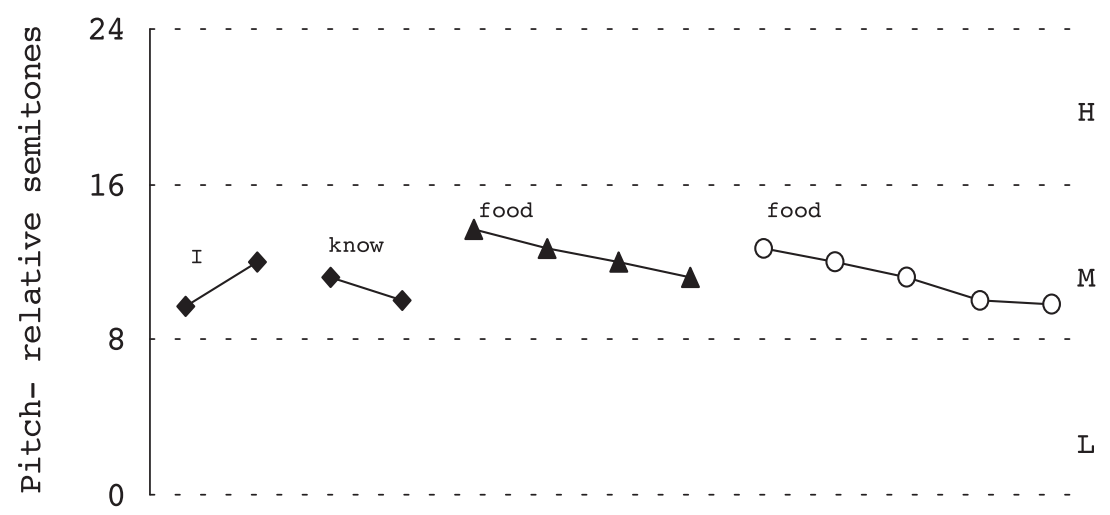

FIGURE 3: Pitch tracks of student response and teacher feedback moves in excerpt (3).

level with a slightly falling contour, almost precisely matching the intonation of Faith's response. The matching pitch level and contour of the teacher's feedback, along with the lexical repetition, form an embodied auditory, lexico-semantic re-creation. One difference in prosodic patterning between the student's and teacher's moves is in length: The teacher's feedback move is longer $(540 \mathrm{~ms})$ than Faith's response (400 ms). The use of a lengthened repetition is a resource the teacher has to add salience to the student response by increasing the time that the student's contribution is active in the discourse. The lexical item, the intonation contour and pitch level, and the rhythm of the teacher feedback move all closely copy the student response, and in this way they affiliate with the student feedback move.

Hewings 1992 also noted in his data on teacher feedback that "p tone" (falling contour) is a common way for a teacher to prosodically mark a positive assessment of a student response. The falling contour of the teacher's feedback and mid pitch level are a closing prosody that indicates mutual understanding has been achieved and further negotiation is not necessary. The duration of the teacher's move adds further comment to the student response, displaying to the student and the class as a whole that the response move is an appropriate reply to the teacher's initiating question. The teacher's prosodic packaging of the lexical repetition in the feedback move, I propose, is part of the linguistic and cultural context for the classroom discourse practice of making a positive assessment of a student response.

Another example in which prosody is part of the construction of a positive assessment is seen in (4). In a grade 12 physics class, the teacher is discussing different types of waves and wave motions (transverse and longitudinal waves; compression and rarefaction). When student Len (line 1) asks for an explanation of rarefaction, the teacher (line 2), holding a large spring, models the position of 


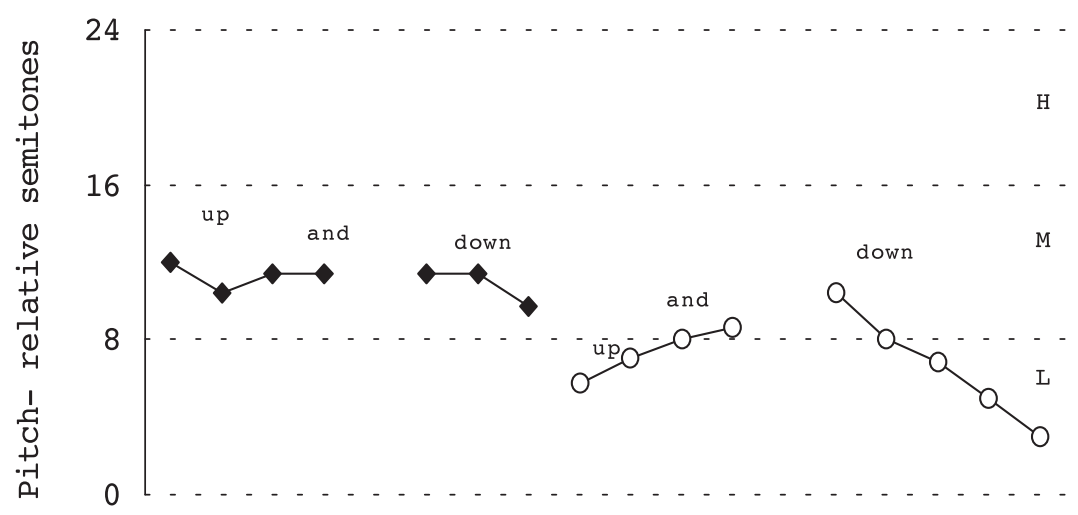

FIGURE 4: Pitch tracks of student response and teacher feedback in excerpt (4).

waves, pulling the spring apart while saying this is rarefaction and pushing the spring back together while saying that's compression. At line 4 , the teacher asks a polar question to the statement in line 3, the air molecules are just moving back and forth. Such a "choice question" (Mehan 1979) asks the students to choose between two items (back and forth or up and down), one of which (back and forth) the teacher has just given. The teacher's question, if it were a water wave, the air molecules would be moving how, is answered by Edith (line 6), and the teacher repeats Edith's response (line 7).

The teacher's feedback move (line 7) falls in the tempo of the exchange that he started in line 4 and that Edith's response continued.

(4) [6jen 38:55]

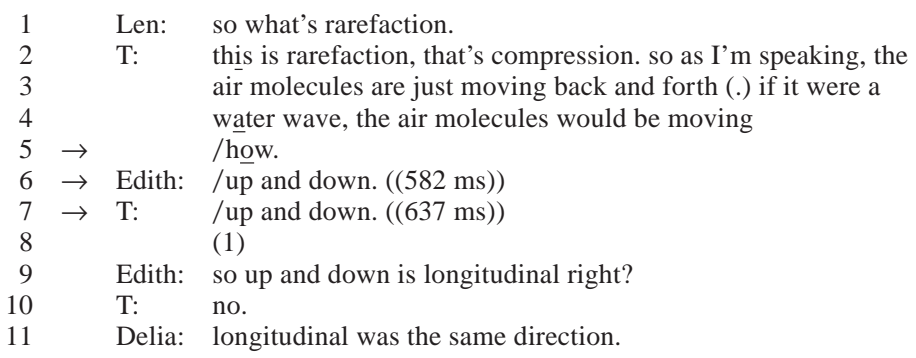

The teacher's feedback move follows in the same rhythm and is slightly longer than the student response ( $637 \mathrm{~ms}-582 \mathrm{~ms}$ ). It is followed by a one-second pause before Edith asks about another point of terminology.

As in (3), the intonation of the teacher's repetitive feedback move in ex. 4, (line 6), is much the same as that of the student response move it repeats: mid pitch level with a falling contour (see Figure 4). 
The prosodic cues in the teacher repeats in (3) and (4) are characteristic of the prosody of most of the repetition types of feedback, based on analysis of more than 100 teacher repetitions in IRF exchanges from my data set. The prosodic packaging of the teachers' turns in (3) and (4) shows how teachers can use prosody in repetition to revoice student contributions in a way that acknowledges the student response as relevant by lengthening the student's words slightly. The teacher's relative matching of student pitch level and intonation contour in the repetition also indexes alignment with the student's contribution (Müller 1996, Tarplee 1996). A second speaker's choice of pitch level is always done in relation to the pitch level of the previous speaker's turn, and pitch matching is a preferred prosody for the second speaker (Brazil et al. 1980:75). In my data, the instances of teacher repetition with the discourse function of indexing a positive evaluation of the immediately preceding student response were accompanied by such affiliative prosodic packaging. I can conclude that teachers most often use repetition in IRF exchanges to make such positive evaluations, and that these are marked by a recurring prosodic embodiment.

\section{Teacher repetition doing other interactive work}

When teachers repeat student responses in IRF exchanges but use a set of prosodic cues that are different from those used to mark positive assessment, what interactional or discourse structuring work do these prosodic cues serve? The following examples show two types of interactive work that such variations in prosody can index.

In (5), a student response is made at a point in the sequence of talk where it appears that the teacher neither elicited nor anticipated student participation. Before this excerpt, the teacher had introduced the topic of the United States' declaration of war in World War II. To find out how this declaration came about, she points students to a set of documents, the reminiscences of a participant in the event (the secretary of war). In lines 18 and 19, the teacher is asking a second question about a particularly short reading passage (labeled "document A"). At line 20, a student, Emi, gives a candidate answer in overlap with the teacher's initiation move:

(5) [47pen 15:42]

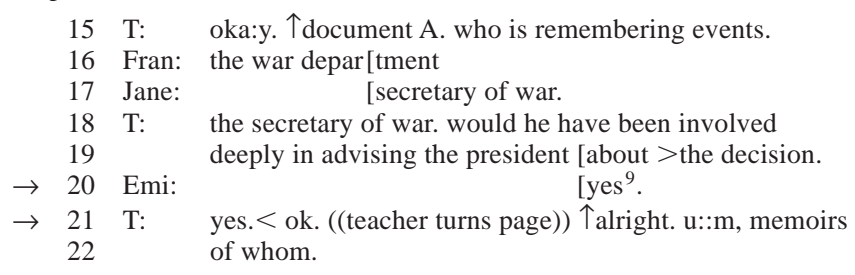

At line 19, we see the teacher orienting to the overlap caused by Emi's response turn at line 20, and doing work to minimize it by rushing through to the end of her 


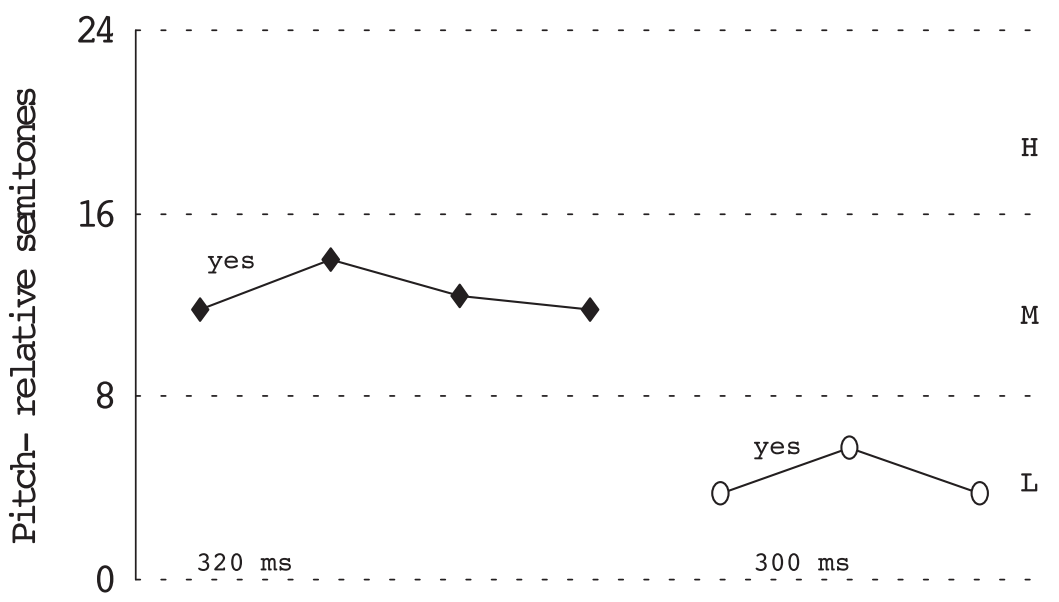

FIGURE 5: Pitch tracks of student response and teacher feedback in excerpt (5).

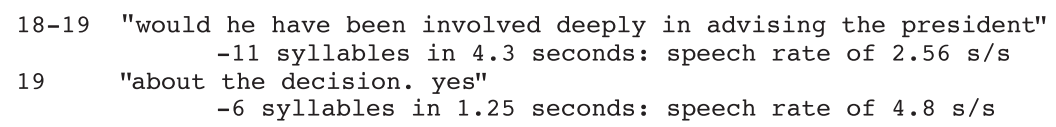

FIGURE 6: Change in speech rate in teacher's talk, lines 18-19.

turn (Schegloff 1982). Figure 6 shows the precise speech rate of the teacher's talk before and after the student response.

After Emi's overlapping response move, the teacher repeats Emi's response at line 21. Although the intonation contour of the teacher's repetition is similar to Emi's, the pitch level of the repeat is notably low in the teacher's pitch range, markedly different from (3) and (4), where the teacher's repetition matches both the pitch level and intonation contour of the student response. Furthermore, the teacher's repeat is not longer in duration, as it was in the repetitions of positive assessment. The duration of Emi's response is $320 \mathrm{~ms}$, while the teacher's repetition is $300 \mathrm{~ms}$. The teacher's rush through in completing her initiating question and the lack of pitch-level matching in her repetition treats the student's response move in a non-routine way. The student's placement of her response in the IRF exchange is at a syntactically complete but intonationally incomplete point in the teacher's initiating move (Ford \& Thompson 1996). Emi's overlapping response (Jefferson 1973) may display to the teacher that the student understands what the teacher is presenting and wants to move on to a new question. The teacher's 
repeat of that overlapping student response does several things: It acknowledges the response as correct, but its prosodic packaging - low pitch level and lack of lengthening - indicates to Emi and to the class that the teacher is closing the questioning on document $\mathrm{A}$, turning the page, and moving on to the next topic. The teacher's use of low pitch level here is one prosodic resource for closing a topic of discussion (Brazil 1997). The teacher's prosody in (5) differs from the repetition in (3) and (4), where the teacher used mid pitch level and longer duration for the repeat to construct a positive assessment of student responses.

In (6), from the physics class, we see a more mixed set of prosodic cues used in an IRF exchange, with repetition by the teacher in line 28 . The teacher's repetition with this particular prosodic packaging can be seen as part of his complex assessment of a student response. Before the start of this excerpt, the teacher had introduced electrical current and resistance and set up a display to show how electrical current is transformed into heat by making a primitive cooking device. He has an electrical plug with exposed wires. He is planning to attach the wires to two nails, which are protruding through a small board, and then cook a hot dog on the nails. He has plugged the wires into the wall socket and is asking the students what would happen if he touched the exposed wires:

(6) [25jen 13:24]

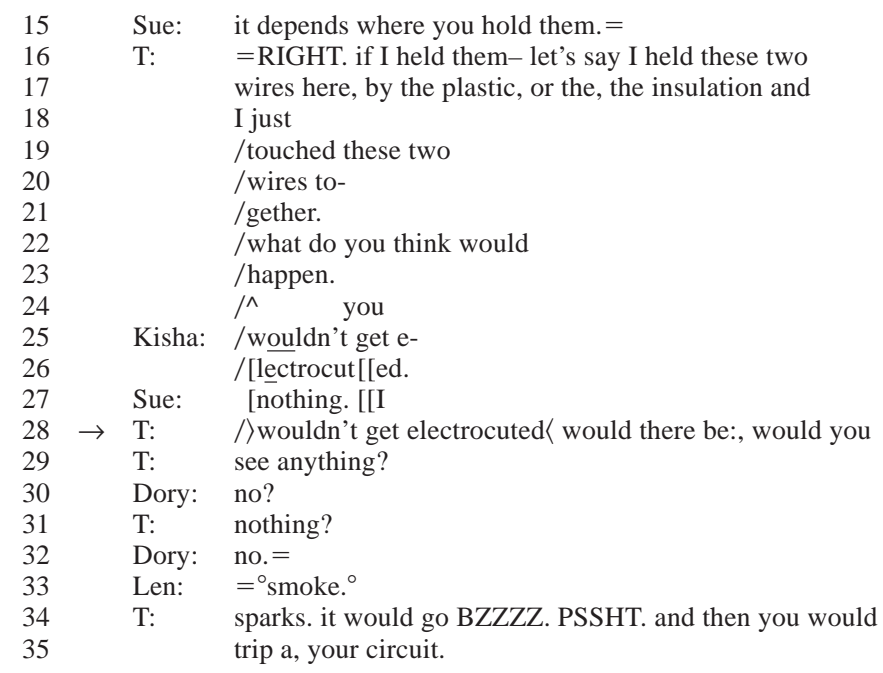

Looking at the rhythm and pace of the teacher's repetition gives the first insight into the complex interactive work of sound production in this case. The rhythmic trajectory of the teacher's feedback move in line 28 expresses affiliation with Kisha's response at lines 24-26. Before the teacher's initiating question in lines 22-23 (what do you think would happen), a rhythmic pattern had been established starting in line 19 on the word touched. The students' (Kisha's and Sue's) 


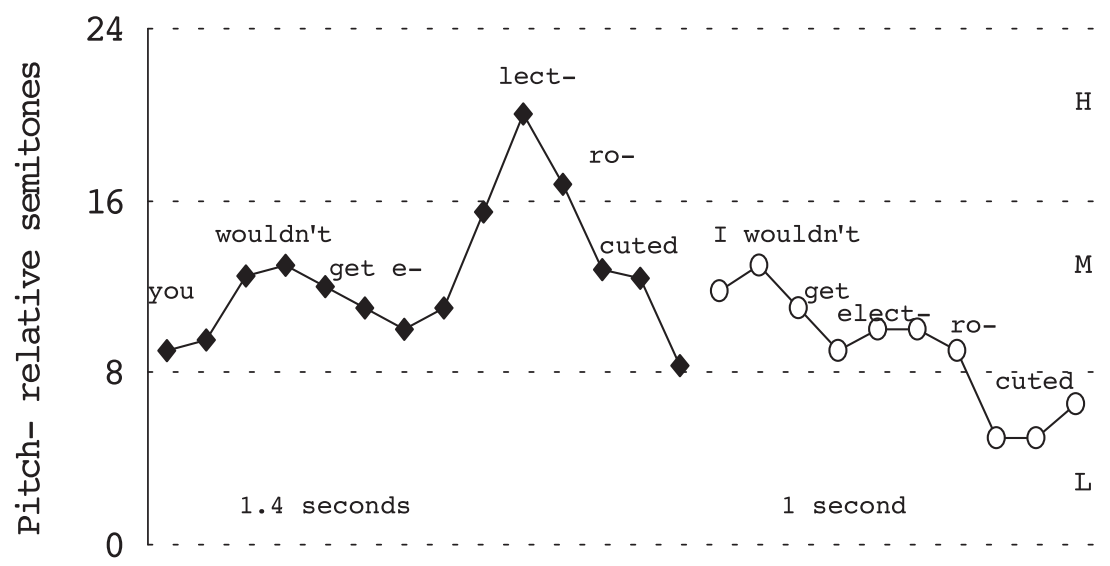

FIGURE 7: Pitch tracks of student response and teacher feedback in excerpt (6).

responses and the teacher's feedback move all occur in synch with this rhythmic pattern.

The intonational patterning of the teacher's repetition at line 28 is another prosodic element used to embody a complex assessment. These cues are shown in Figure 7. The teacher's feedback move (line 28) is made in the mid pitch range, but slightly lower than the student response moves at lines 24-27. The termination of the teacher's intonation contour also has a slight rise, indicating continuation. Looking at the sequence of talk that occurs after this IRF, we see that the teacher is looking for a different answer than he gets from Kisha in lines 24-26. After the teacher's second initiation on this topic in lines 28-29 (would you see anything?), several students offer candidate answers that are not ratified by the teacher. After Len's candidate answer in line 33, smoke, the teacher gives the answer (line 34) that he has been trying to lead the students to - sparks.

Although the pitch peak of the teacher's feedback move is in the mid pitch range, it is produced at a lower level than the student's answer at line 24-26. The pitch contour also indicates that the teacher is revoicing the student response to indicate something more is needed. The pitch peak for the teacher's repetition is on the first syllable of wouldn't, while in the student answer the pitch peak is on the second syllable of electrocuted. Using the contrasting pitch accent, the teacher refocuses the stress to wouldn't and uses a rising intonation contour on electrocuted. While the student pitch contour has a final fall, the slightly rising intonation contour at the end of the teacher's utterance keeps the lexical item electrocuted open for negotiation. A feedback move at a high pitch level would indicate that the teacher felt it necessary to comment on the student response (Brazil et al. 1980, Brazil 1997); but the teacher's mid level feedback move with a slightly rising ending pitch contour seems to indicate the teacher's stance that, while the 
TABLE 2. Speech rate of moves in excerpt (6).

\begin{tabular}{llll}
\hline \hline $22-23$ & I & what do you think would happen & $(7 / 1.04-6.73 \mathrm{~s} / \mathrm{s})$ \\
$24-26 \mathrm{R}$ & you wouldn't get electrocuted & $(9 / 1.40-6.43 \mathrm{~s} / \mathrm{s})$ \\
$\mathbf{2 7 - 2 8 ~ F}$ & I wouldn't get electrocuted & $(\mathbf{9 / 1 . 0 3 - 8 . 7 3} \mathrm{s} / \mathbf{s})$ \\
$28 \quad$ pre-I & would there be & $(3 / .810-3.71 \mathrm{~s} / \mathrm{s})$ \\
29 & I & would you see anything & $(6 / .910-6.59 \mathrm{~s} / \mathrm{s})$ \\
31 & $\mathrm{I}$ & nothing & $(2 / .480-4.16 \mathrm{~s} / \mathrm{s})$ \\
$\mathbf{3 4 - 3 5} \mathbf{~ F}$ & $\begin{array}{l}\text { sparks. it would go BZZZZ PSSHT and } \\
\text { then you would trip a, your circuit }\end{array}$ & \\
& & $\mathbf{( 1 5 / 5 . 5 - 2 . 7 2} \mathrm{s} / \mathbf{s})$ \\
\hline
\end{tabular}

student response is not incorrect, it is not complete. The slightly lower pitch level of the teacher's feedback move doesn't necessarily indicate disaffiliation with the student's response, but perhaps mitigation of a dispreferred feedback move and a lack of engagement with that particular response.

Looking turn by turn at the pace of the teacher's moves, we can see an effort to highlight some student words and minimize others. In excerpts (3) and (4), showing use of repetition for positive assessment, we saw that the repetitive teacher feedback moves were longer in duration than the student responses. In (6), the teacher's repetition of the student response is slightly shorter in duration (1.03 seconds to 1.4 seconds for Kisha's response at lines 24-26). Table 2 outlines the speech rate of the initiation, response, and feedback moves in the sequence of talk from (6).

The teacher's repetitive feedback move in lines $27-28$ is faster-paced than the surrounding talk, and much faster-paced than the other feedback move in this sequence (line 34). This repetition and its faster pace simultaneously acknowledge the student response as not incorrect and proceeds to another, more specific initiation move on the same topic. The sequence of talk that occurs after this IRF and repetition indicates that the teacher is looking for a different answer than he gets from Kisha (lines 24-26). The teacher's second initiation on this topic in line 29 is a "product elicitation" (Mehan 1979:43), in which teachers ask students for a particular answer from a range of choices. At lines 27-28, the teacher uses repetition with particular prosody (lower pitch level, faster pace, different pitch peaks, and rising pitch contour) as part of a set of linguistic resources to show both his partial acceptance of Kisha's candidate answer and a trajectory to continue the search for a more complete answer, or, at least, the answer he has in mind.

Orientation to gap as dispreferred feedback. The rhythmic timing and lack of repetition of the feedback part of the triadic dialogue is so much a part of its production that students can be seen to orient to the absence of the feedback move 
in its rhythmically timed slot. Excerpt (7), from the physics class, shows the teacher asking a question of students (lines 1-5). At lines 5-7, Andy and Jim give candidate answers. However, their answers are not followed by a teacher repeat or evaluative marker. Instead, there is a 1.5-second pause, after which the teacher produces a minimal acknowledgment token (okay), using an equivocal-sounding intonation contour (two-tiered falling) at the low pitch level. The pause and equivocal intonation prompt another student's attempt (Edith, lines 8-9) at upgrading or improving on the first answer:

(7) $[12$ jen $32: 07]$

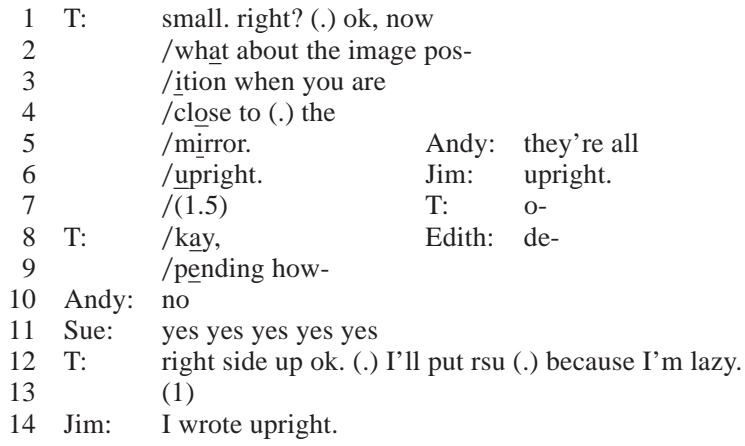

In studies of conversation, a short pause after first turns such as assessments, questions, or offers has been shown to be a marker of a dispreferred response (Levinson 1983, Davidson 1984, Pomerantz 1984, Sacks 1987). A similar format for projecting a dispreferred response can be seen in participants' orientation to the sequential organization in the IRF exchange in classroom discourse.

Rhythm can also be seen as a prosodic feature to which participants in classroom discourse orient. Excerpt (7) shows the teacher's initiation move (lines 2-5) setting up a rhythmical stretch of talk. Andy's response (end of line 5 and line 6) is made in synch with the rhythmic pattern, but in the rhythmic slot for the teacher's feedback move, there is a 1.5-second gap. The teacher's okay token (lines 7-8) occurs after the gap in rhythm. Edith's attempt at a clarification or upgrade (lines 8-9) of what she perceives as Andy's and Jim's incorrect responses is then also placed within the established rhythmical sequence.

The example highlighted in (7) shows that students orient to the rhythmical outline of each move in an IRF exchange. The absence of the teacher feedback move in the rhythmic position of the third slot is taken by students as a dispreferred move by the teacher and a negative assessment - a third-position repair initiation (Schegloff 1979, McHoul 1990). Students take this as cause to do work to repair the previous response turn within the IRF exchange. In this way, they orient to the timing of the teacher as part of what constitutes the IRF exchange. 
The teachers' use of repetition in feedback moves to students in examples (3-7) allows us to investigate the interactive use of the prosodic resources available for teachers to revoice student responses in IRF exchanges. Looking at pitch level and contour, and at syllable duration and rhythm, we see that teachers may choose different configurations of prosodic resources to help embody the type of interaction they want to accomplish. In (5)and (6), the teachers acknowledge the student responses by repeating lexical items, but the differential prosody of each repetition suggests that the teacher is also trying to accomplish some additional interactive work. In (5), the teacher, orienting to the student's overlapping response move, repeats the student contribution at a lower pitch level to acknowledge the student's understanding of the issue she was explaining, while at the same time closing the questioning session for a particular text. In (6), a student response is acknowledged as not irrelevant to the topic by the teacher's use of a mid-pitch-level repeat. The continuation of the talk shows that the teacher has another answer in mind; by mismatching his intonation contour and speeding up the pace of his talk, he makes that lexical repetition work to move the discourse on toward the answer he is trying to elicit.

Brazil has discussed the use of low key by a second speaker as "restrictive" (Brazil et al. 1980), in that the speaker is acknowledging both that the previous turn is relevant and that more commentary is not necessary. In (5), the lexical repeat of the teacher's feedback move can be seen as an acknowledgment of a student response, while the low pitch level indexes a lack of projected continuation or expansion of the topic of that student response. In (6), the prosodic resources assume some of the mitigating work that teachers do in classroom discourse to lessen their authority (Cazden 1988). Instead of using low pitch level, the dispreferring feedback move by the teacher is mitigated by the use of mid pitch level and the in-synch rhythmical placement of the feedback move. But the teacher's feedback move also uses a different pitch contour than that of the student response, and the words are produced more quickly, to move away from what the teacher considers an incomplete student response. Timing is also seen to be a prosodic device within the IRF exchange: When the rhythmic slot for the teacher's feedback move is not filled, as in (7), students orient to its absence as a negative assessment and offer alternate responses.

The findings in this project lend empirical support to the theory of the communicative value of intonation (Brazil 1997). Close analysis of the IRF exchanges has shown that teachers and students use intonation contours (tone) as part of their systematic work toward convergence in classroom discourse. The proclaiming tone (falling contour) used in minimal response formats (e.g. student answer after teacher question) fulfills the expectation in the initiation move, which is movement to a new point of convergence or shared information. In the two-line excerpt from conversation in (8), the falling intonation in B's response in line 2 


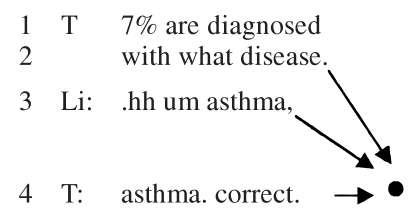

1 A: where's the car.
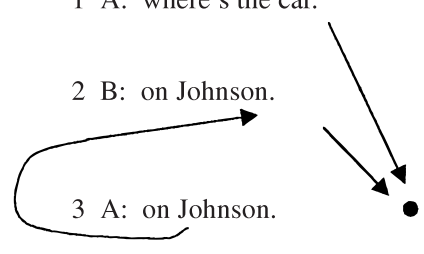

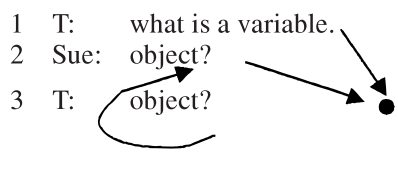

1 A: where's the car

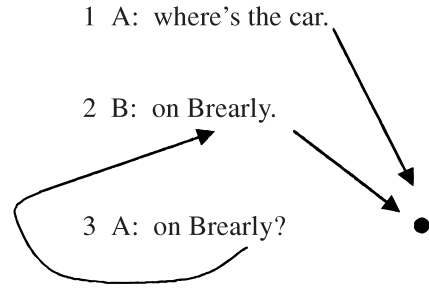

FIGURE 8: Schematic representation of discourse moves in excerpts (9) and (10).

completes what A's turn began: the request for information. The rightward arrow is Brazil's schematic representation of movement to a new point of convergence.

(8) [household]

1 A: Where's the car.

2 B: On Ingersol.

Looking at repetition in the third slot of a sequence of talk in interaction, we see that the use of different intonation contours distinguishes institutional discourse, like that of the classroom, from everyday conversation. In classroom discourse (see $9 \mathrm{a}-\mathrm{b}$ ), teachers use falling or rising intonation contours with repetition in their feedback to student responses to accomplish different kinds of interactional work.

(9a) [33wal46:08]

$1 \mathrm{~T} \quad 7$ percent are diagnosed

2 with what disease.

3 Li: .hh um asthma,

4 T: asthma. correct. (9b) [33wal 44:31]

$1 \mathrm{~T}$ : what is a variable.

2 Sue: object?

3 T: object?

The drawings in Figure 8, accompanying excerpts (9) and (10), are adaptations of Brazil's (1997). The straight arrows directed at the bullet represent movement of the discourse to a new point of convergence, while the looping arrows symbolize the discourse remaining at the present state of shared understanding. In the classroom example (9a), the three turns in the exchange are marked with arrows to a single point, indicating the convergence of the participants on a new point of information. The teacher's repetitive feedback move (line 3), with falling intonation contour, indicates receipt of the information, a new point of convergence, 
and closure of the topic. In (9b), convergence on the new point of information is disrupted by the teacher's repetition and rising contour (line 3). The schematic representation indicates that the teacher's use of the rising contour brings the focus of information back to the student's turn.

Unlike classroom discourse, in everyday conversation the use of intonation contour to differentiate between different assessments is not an option for the speaker in the third slot, as shown in $(10 \mathrm{a}-\mathrm{b})$. The use of repetition in this third slot, regardless of its intonational embodiment, indicates trouble of some kind. In examples from everyday conversation in (10a-b), the schemata (Fig. 8) show that both falling and rising contours in the third turn repetitions throw the focus back on the second turn and hold the discourse at the present state of convergence:

(10a)

1 A: where's the car.

2 B: on Johnson.

3 A: on Johnson.

4 B: What's wrong. (10b)

1 A: where's the car.

2 B: on Brearly.

3 A: on Brearly?

4 B: I mean Ingersol.

The examples in (9) show how intonation plays a role in determining the interpretation of the status of information given in the second turn by students. This use of intonation in the third turn of the IRF exchange seems to be a distinguishing characteristic of classroom or other institutional discourse.

The regular prosodic packaging in teachers' feedback moves (mid pitch level, falling contours) presented here show the embodied practice that teachers use in determining to what degree student responses are integrated into the ongoing discourse. The prosodic packaging of the teachers' repetitions also work to shut out any diversion or expansion by students. Researchers have commented on the unequal distribution of power reflected in the IRF exchange (Lemke 1990): The teachers' slots are expandable while the students' second slot, the response slot, is delimited by its surrounded place in the sequence, where the teacher can control often through prosody the trajectory of the discourse following a student response. Cazden (1988) and Nystrand (1997) have both characterized classroom discourse as often made up of sequences of "recitation" in which series of teacher questions and student responses to them create a rigid sequence of IRF exchanges. Although I would hesitate to call these sequences of talk "recitation," I have outlined the embodiment of these classroom discourse practices in systematic sound patterns.

Prosody in the teachers' feedback move is used systematically as part of indexing either a positive assessment and the end of a particular IRF exchange, or an assessment that a student response is somehow incomplete and an extension of the issue beyond the three-turn IRF is warranted. My findings give evidence that the IRF exchange is pervasive in classroom discourse, but not inflexible. The interactional import of this exchange is determined by the way the exchange is produced in time and in voice. 


\section{NOTES}

* I would like to thank Cecilia Ford, Ann Wennerstrom, Christina Higgins, Jane Hill, and two anonymous reviewers for their excellent feedback on earlier versions of this article. Any errors or inconsistencies that remain are the responsibility of the author.

${ }^{1}$ A complete discussion of relative versus absolute pitch follows in the fourth section.

${ }^{2}$ For other analyses of prosody in classroom discourse focusing on the teacher, see Wennerstrom 1994, 2001, and Pickering, 1999, 2001.

${ }^{3}$ By "prosody," I refer to the analysis of sound phenomena in language, which includes pitch both intonation contour and pitch level or key - as well as timing, which includes pause, syllable length, and rhythm. Initial observations of prosodic phenomena were made auditorily and then checked acoustically. Tracks for fundamental frequency have been made using a perceptual scale indicating pitch in semitones and are displayed in the figures on a scale of relative semitones (see 't Hart et al. 1990, Couper-Kuhlen 1996).

4 The data for this article were originally collected as part of a project entitled "The socialization of diverse learners into subject matter discourse" (Principal investigators Jane Zuengler, and Cecilia Ford). The project is part of the Center on English Learning and Achievement (CELA), which is supported by the US Department of Education's Office of Educational Research and Improvement (Award \#R305A60005). However, the views expressed in this article are those of the author and do not necessarily represent the views of the principal investigators, CELA, or the U.S. Department of Education.

${ }^{5}$ For an explicit discussion of the methods for data collection, see Zuengler, Fassnacht \& Ford 1998.

${ }^{6}$ For research showing the necessity of using auditory judgments in the analysis of prosody in language in use, see 't Hart \& Cohen 1973, Schuetze et al. 1992, and Couper-Kuhlen 1993.

7 Although the term "register" has been used to discuss pitch level in spoken language (Crystal 1969, Cruttenden 1986) and may be less cumbersome than "pitch level," it carries meanings from other areas of linguistics, such as speech style or genre (Halliday 1978) and phonological pitch level (Ladd 1996). The term is also used in the description of voice ranges in music. For these reasons, I avoid the use of "register" here (cf. Couper-Kuhlen 1996).

${ }^{8}$ In this transcription format, regularly timed occurrences of prominent syllables (rhythmic stretches of talk) are indicated by the '/' marking at the start of the row. Prominent syllables are placed first in the row (cf. Couper-Kuhlen 1993; Auer et al. 1999).

${ }^{9}$ An anonymous reviewer justifiably questioned how pitch tracks can be made at points of overlapping talk. Having sound recordings from two cameras in the classroom sometimes allowed separation between the voices of teacher and students; one camera captured the students' voices while the other picked up the teacher's. More often, however, auditory judgments were used to augment short stretches of the acoustic pitch tracks that lacked clarity.

\section{REFERENCES}

Adger, Carolyn, \& Hoyle, Susan (2001). Authorship in professional training talk. Paper presented at the American Association of Applied Linguistics Conference, St. Louis, MO, 25 Feb. 2001.

Atkinson, John M., \& Heritage, John C. (eds.) (1984). Structures of social action: Studies in Conversation Analysis. Cambridge: Cambridge University Press.

Auer, Peter (1996). On the prosody and syntax of turn continuations. In E. Couper-Kuhlen \& M. Selting (eds.), Prosody in conversation: Interactional studies, 57-100. Cambridge: Cambridge University Press. \& di Luzio, Aldo (eds.) (1992). The contextualization of language. Amsterdam: John Benjamins.

; Couper-Kuhlen, Elizabeth; \& Müller, Frank (1999). Language in time: The rhythm and tempo of spoken interaction. New York: Oxford University Press.

Bean, Martha, \& Patthey-Chavez, G. Genevieve (1994). Repetition in instructional discourse: A means for joint cognition. In Barbara Johnstone (ed.), Repetition in discourse: Interdisciplinary perspectives, volume 1, 207-20. Norwood, NJ: Ablex.

Blankenship, Jane, \& Kay, Christian (1964). Hesitation phenomena in English speech. Word 20:360-72. Bolinger, Dwight (1961). Syntactic blends and other matters. Language 37:366-81. 
(1976). Meaning and memory. Forum Linguisticum 1:1-14.

Brazil, David (1976). The teacher's use of intonation. Educational Review 28:180-89.

(1997). The communicative value of intonation in English. Cambridge: Cambridge University Press.

; Coulthard, Malcolm; \& Johns, Catherine (1980). Discourse intonation and language teaching. London: Longman.

Cazden, Courtney B. (1988). Classroom discourse: The language of teaching and learning. Portsmouth, NH: Heinemann.

Chafe, Wallace (1988). Linking intonation units in spoken English. In John Haiman \& Sandra A. Thompson (eds.), Clause combining in grammar and discourse, 1-27. Amsterdam: John Benjamins. Couper-Kuhlen, Elizabeth. (1986). An introduction to English prosody. London: Edward Arnold. (1990). Speech rhythm at turn transitions: Its functioning in everyday conversation. KontRI Arbeitspapiere des Projekts "Kontextualisierung durch rhythmus und intonation", Fachgruppe Sprachwissenschaft, 8. University of Konstanz. $337-64$.

(1992). Contextualizing discourse: The prosody of interactive repair. In Auer \& di Luzio,

(1993). English speech rhythm: form and function in everyday verbal interaction. Amsterdam \& Philadelphia: John Benjamins.

(1996). The prosody of repetition: on quoting and mimicry. In Couper-Kuhlen \& Selting, $366-405$.

(1998). Coherent voicing: On prosody in conversational reported speech. InLiSt: Interaction and Linguistic Structure, 1. University of Konstanz.

, \& Auer, P. (1988). On the contextualizing function of speech rhythm in conversation: Questionanswer sequences. KontRI, Arbeitspapiere des Projekts "Kontextualisierung durch rhythmus und intonation”, Fachgruppe Sprachwissenschaft, 1. University of Konstanz.

(1991). On the contextualizing function of speech rhythm in conversation: Questionanswer sequences. In J. Verschueren (ed.), Levels of linguistic adaption: Selected papers of the 1987 International Pragmatics Conference, vol. 2, 1-18. Amsterdam: John Benjamins.

\& Selting, Margret (eds.) (1996). Prosody in conversation: Interactional studies. Cambridge: Cambridge University Press.

Cowley, Stephen J. (1998). On timing, turn-taking and conversation. Journal of Psycholinguistic Research 22:541-71.

Cruttenden, A. (1986). Intonation. Cambridge: Cambridge University Press.

Crystal, David (1969). Prosodic systems and intonation in English. Cambridge: Cambridge University Press.

Davidson, Judy (1984). Subsequent versions of invitations, offers, requests, and proposals dealing with potential or actual rejection. In J. M. Atkinson \& J. Heritage (eds.), Structures of social action, 102-28. Cambridge: Cambridge University Press.

Erickson, Frederick (1981). Money tree, lasagna bush, salt and pepper: Social construction of topical cohesion in a conversation among Italian-Americans. In Deborah Tannen (ed.), Analyzing discourse: Text and talk, 43-70. Washington, DC: Georgetown University Press.

(1992). They know all the lines: Rhythmic organization and contextualization in a conversational listing routine. In Auer \& di Luzio 365-97.

\& Schultz, Jeffry (1982). The counselor as gatekeeper. New York: Academic Press.

Fiksdal, Susan (1990). The right time and pace. Norwood, NJ: Ablex.

Goffman, Erving (1974). Frame analysis: An essay on the organization of experience. New York: Harper \& Row.

Gósy, Mária (1991). The perception of tempo. In M. Gósy (ed.), Temporal factors in speech, 63-106. Budapest: MTA Nyelvtudományi Intézete.

Halliday, Michael A. K. (1978). Language as social semiotic: The social interpretation of language and meaning. London: Edward Arnold.

\& Hasan, Ruqaiya (1976). Cohesion in English. London: Longman.

't Hart, Johan, \& Cohen, Antoine (1973). Intonation by rule: A perceptual quest. Journal of Phonetics $1: 309-27$.

; Collier, Rene; \& Cohen, Antoine (1990). A perceptual study of intonation: An experimentalphonetic approach to speech melody. Cambridge: Cambridge University Press. 
Hewings, Martin (1992). Intonation and feedback in the EFL classroom. In Malcolm Coulthard (ed.), Advances in spoken discourse analysis, 183-96. London: Routledge.

Jefferson, Gail (1972). Side sequences. In David Sudnow (ed.), Studies in social interaction, 294338. New York: Free Press.

Jefferson, Gail (1973). A case of precision timing in ordinary conversation: Overlapped tag-positioned address terms in closing sequences. Semiotica 9:47-96.

Johnstone, Barbara (ed.) (1994). Repetition in discourse: Interdisciplinary perspectives. 2 vols. Norwood, NJ: Ablex.

Ladd, D. R. (1996). Intonational phonology. Cambridge: Cambridge University Press.

Lemke, Jay (1990). Talking science: Language, learning, and values. Norwood, NJ: Ablex.

Levinson, S. (1983). Pragmatics. Cambridge: Cambridge University Press.

Local, John (1996). Conversational phonetics: Some aspects of news receipts in everyday talk. In Couper-Kuhlen \& Selting, 177-230.

McHoul, Alexander W. (1990). The organization of repair in classroom talk. Language in Society 19:349-77.

Mehan, Hugh (1979). Learning lessons: Social organization in the classroom. Cambridge, MA: Harvard University Press.

Mercer, Neil (1992). Talk for teaching-and-learning. In K. Norman (ed.), Thinking voices: The National Oracy Project, 215-23. London: Hodder \& Stoughton.

(1995). The guided construction of knowledge: Talk among teachers and learners. Clevedon: Multilingual Matters.

Müller, Frank E. (1996). Affiliating and disaffiliating with continuers: Prosodic aspects of recipiency. In Couper-Kuhlen \& Selting, 131-76.

Nassaji, Hossein, \& Wells, Gordon (2000). What's the use of "triadic dialogue"?: An investigation of teacher-student interaction. Applied Linguistics 21:376-406.

Newman, Denis; Griffin, Peg; \& Cole, Michael (1989). The construction zone: Working for cognitive change in school. Cambridge: Cambridge University Press.

Norrick, Neil R. (1987). Functions of repetition in conversation. Text 7:245-64.

Nystrand, Martin (1997). Opening dialogue. New York: Teachers College Press.

\& Gamoran, Adam (1991). Instructional discourse, student engagement, and literature achievement. Research in the Teaching of English 25:261-90.

Orsolini, Margherita, \& Pontecorvo, Clotilde (1992). Children's talk in classroom discussions. Cognition and Instruction 9:113-36.

Pickering, Lucy (1999). An analysis of prosodic systems in the classroom discourse of native speaker and nonnative speaker teaching assistants. Dissertation, University of Florida, Gainesville.

(2001). The role of tone choice in improving ITA communication in the classroom. TESOL Quarterly 35:233-55.

Pierrehumbert, Janet (1980). The phonology and phonetics of English intonation. Bloomington: Indiana University Linguistics Club.

Pomerantz, Anita (1984). Agreeing and disagreeing with assessments: Some features of preferred/ dispreferred turn shapes. In Atkinson \& Heritage, 57-101.

Psathas, George. (1995). Conversation Analysis. Thousand Oaks, CA: Sage.

Sacks, Harvey (1987). On the preferences for agreement and contiguity in sequences in conversation. In Graham Button \& John R. E. Lee (eds.), Talk in social organisation, 54-69. Clevedon: Multilingual Matters.

; Schegloff, Emanuel; \& Jefferson, Gail. (1974). A simplest systematics for the organization of turn-taking for conversations. Language 50:696-735.

Schegloff, Emanuel A. (1979). The relevance of repair to syntax-for-conversation. In Talmy Givon (ed.), Syntax and semantics: Discourse and syntax, 261-86. New York: Academic Press.

(1982). Discourse as an interactional achievement: Some uses of "uh huh" and other things that come between sentences. In Deborah Tannen (ed.), Analyzing discourse: Text and talk, 71-93. Washington, DC: Georgetown University Press.

(1996a). Confirming allusions: Toward an empirical account of action. American Journal of Sociology 102:161-216.

(1996b). Turn organization: One intersection of grammar and interaction. In Elinor Ochs et al. (eds.), Interaction and grammar (pp. 52-133). Cambridge: Cambridge University Press. 
(1998). Reflections on studying prosody in talk-in-interaction. Language and Speech 41:235-63.

; Jefferson, Gail; \& Sacks, Harvey (1977). The preference for self-repair in the organization of repair in conversation. Language 53:361-82.

Schuetze-Coburn, Stephen; Shapley, Marian; \& Weber, Elizabeth G. (1992). Units of intonation in discourse: A comparison of acoustic and auditory analyses. Language and Speech 34: 207-34.

Scollon, Ronald (1981). The rhythmic integration of everyday talk. In Deborah Tannen (ed.), Analyzing discourse: Text and talk, 335-49. Washington, DC: Georgetown University Press.

\& Scollon, Suzanne W. (2001). Intercultural communication. 2nd ed. London: Blackwell.

Selting, Margret (1987). Descriptive categories for the auditive analysis of intonation in conversation. Journal of Pragmatics 11:777-91.

(1992). Prosody in conversational questions. Journal of Pragmatics 17:315-45.

(1998). TCUs and TRPs: The construction of units in conversational talk. Potsdam: Interaction and Linguistic Structures, Universitat Potsdam.

Shimanoff, Susan, \& Brunak, Joanna (1977). Repairs in planned and unplanned discourse. In Elinor Keenan \& T. Bennett (eds.), Discourse across time and space, vol. 5, 123-67. Los Angeles: Department of Linguistics, University of Southern California.

Simpson, JoEllen M. (1994). Regularized intonation in conversational repetition. In Johnstone, vol. 2, 41-49.

Sinclair, John McHugh, \& Brazil, David (1982). Teacher talk. Oxford: Oxford University Press. \& Coulthard, Malcolm (1975). Towards an analysis of discourse: The English used by teachers and pupils. London: Oxford University Press.

Tannen, Deborah (1987). Repetition in conversation as spontaneous formulaicity. Text 7:215-43. (1989). Talking voices: Repetition, dialogue and imagery in conversational discourse. Cambridge: Cambridge University Press.

Tarplee, Claire (1996). Working on young children's utterances: Prosodic aspects of repetition during picture labelling. In Couper-Kuhlen \& Selting, 406-35.

Uhmann, Susanne (1992). Contextualizing relevance: On some forms and functions of speech rate in everyday conversation. In Auer \& di Luzio, 297-336.

Wells, Gordon (1993). Reevaluating the IRF sequence: A proposal for the articulation of theories of activity and discourse for the analysis of teaching and learning in the classroom. Linguistics in Education 5:1-37.

(1999). Dialogic inquiry: Toward a sociocultural practice and theory of education. Cambridge: Cambridge University Press.

Wennerstrom, Ann (1994). Intonational meaning in English discourse: A study of non-native speakers. Applied Linguistics 15:399-420.

(2001). The music of everyday speech: Prosody and discourse analysis. New York: Oxford University Press.

Wichmann, Anne (2000). Intonation in text and discourse: Beginnings, middles and ends. Harlow, UK: Longman.

Wood, David J. (1992). Teaching talk: How modes of teacher talk affect pupil participation. In K. Norman (ed.), Thinking voices: The work of the National Oracy Project, 203-14. London: Hodder $\&$ Stoughton.

Zuengler, Jane; Fassnacht, Chris; \& Ford, Cecilia (1998). Analyst eyes and camera eyes: Theoretical and technological considerations in "Seeing" the details of classroom interaction. Report Series 2.40 (11006). Albany, NY: National Research Center on English Learning and Achievement.

(Received 22 July 2001; Final revision received 9 May, 2002) 